\section{Acclimatization in Relation to Livestock Improvement}

The problem of the acclimatization of breeds of livestock exported from one country to another is interesting. Certain breeds quickly adapt themselves to certain environmental conditions far removed from those under which they were reared. But, generally speaking, the importation of domesticated breeds into countries of different climatic and soil conditions is regarded as a somewhat risky enterprise. The genetic constitution of the modern breeds has so changed during the last hundred years that many of them depend entirely upon human assistance, and have lost, to a great degree, the ability to live under natural conditions. If this happens in a country, it may be advisable to import foreign breeds of strong constitution which are better adapted than the local breeds, weakened through the continued use of false standards of selection over many generations.

An example of this is to be seen in the Zoological Garden at Warsaw. The European wild deer (Cervus Elaphus), from the forests which surround that city, when kept in the open paddocks at the Zoo during the winter, are very susceptible to colds, and usually succumb to pneumonia. On the other hand, the spotted wild deer, imported from India, running in similar paddocks and receiving similar treatment, show signs of robust health and maintain good condition throughout the winter. This observation is confirmed by others and appears to hold good for other Mammalia imported to Warsaw from the tropics.

Accordingly, one is forced to the conclusion that the genotype of the European deer has been weakened. These wild deer of Europe are kept under abnormal conditions. Not only is natural selection removed, but also, since the sportsmen shoot the best males, it is the least thrifty specimens that produce the next generation. These wild deer have to be artificially fed during the winter.

Accordingly, consideration of the problem of acclimatization of domesticated animals in European conditions must include the weakened condition of domesticated strains. It appears to me that this emphasizes the need for skilful selection on the part of the breeder of these domesticated strains, and that this is a more important factor in economical production than suitable environmental conditions. But, of course, the progressive breeder will make his choice of the right breed in its right environment.

Jagellonian University,

R. Prawochenski.

Cracow. April 12.

\section{Sources of Calcium for Shell of Ostrea virginica}

THE letter by Robertson and Pantin on "Tube Formation in Pomtoceros triqueter (L)"1 points to the sea water as the source of the calcium required for the building of tubes. It is of interest that a similar condition apparently obtains in the case of Ostrea virginica. My observations in $1932-33^{2}$ on the growth of oysters in Long Island Sound show that the deposition of the shell material continues throughout the winter even when other activities of the organism are reduced to the minimum. The weight of the shell increased when the temperature of the water dropped below $4^{\circ} \mathrm{C}$. and the oysters were in a state of hibernation, unable to take in any food. During the same period the weight of the tissues remained constant.
In view of the fact that there is no storage of calcium in the body of the oyster, an inference can be made that calcium and other salts required for the building of shells are taken in directly from the sea water.

\section{U.S. Bureau of Fisheries, (Senior Biologist.) Washington.}

${ }^{1}$ Nature, 141, 648 (April 9, 1938).

2 "The Biochemistry of the Invertebrates of the Sea", by Paul S Galtsoff, Ecological Monographs, 4, 481-490 (October 1934).

\section{Toxicity of Mercury Vapour to Insects}

Christensen, Krogh and Nielsen ${ }^{1}$ have referred to the highly toxic effects of mercury vapour in a closed experimental chamber, and recorded the effects on mammals of this vapour arising from droplets of mercury spilled accidentally on the chamber floor. Previously Krogh ${ }^{2}$ found a very high mortality among insect embryos on which he was carrying out respira. tion experiments. He attributed this to the toxic action of mercury vapour from minute drops of mercury which were always left in the tap-borings of his air sampling tubes. He states that it was known from unpublished observations of the Copenhagen physiological laboratories that mercury vapour was highly toxic to insect eggs. Burkholder ${ }^{3}$, who cited Krogh's paper, found that eggs of the grasshopper, Melanoplus differentialis Thomas, died in a glass respirometer which had been calibrated with mercury although the mercury had been removed prior to the experiment.

Whilst carrying out toxicity tests on eggs of the bed-bug, Cimex lectularius L., in a fumigation apparatus containing mercury, I observed a high mortality amongst the controls. At $23^{\circ} \mathrm{C}$. all the control eggs were killed in less than twelve hours. I traced this to the effect of mercury vapour, and found that other stages of the bug were only affected after several days' exposure. I also found that eggs of the flour beetle, Tribolium confusum Duv., were all killed within less than twenty-four hours, whereas other stages of this insect were unaffected by exposures of one week.

As mercury is extensively used in biological apparatus and the literature concerning its toxicity is very scattered, a note on the subject may be useful to other workers. The literature cited here does not pretend to be exhaustive, as observations on this phenomenon made by physiologists are not necessarily indicated by the title of the paper in which they are mentioned or noticed by abstractors.

Kunhi Kannan ${ }^{4}$ first directed attention to the custom of Indian peasants of protecting stored pulses from pests by placing a drop of mercury in an excavated soap-nut in the receptacle used for storing. Though the practice had nearly died out, he investigated it and his results showed the value of what had long been regarded as a superstition. He pointed out that the action of the mercury vapour was only on the eggs of the insects concerned. Larson ${ }^{5}$, acting on a suggestion of Kunhi Kannan's, found that both eggs and young larvæ of Bruchus quadrimaculatus $\mathbf{F}$. were killed by exposure to mercury vapour. Dutt and Puri ${ }^{6}$ confirmed the statement that it was insect eggs that were particularly affected, finding it true of several species of stored products pests and other insects. A dust containing metallic mercury as the toxic principle was found to be effective against pests of cereals by Cartwright? 